\title{
Challenges and Perspectives of Nanoparticle Exposure Assessment
}

\author{
Ji Hyun Lee, Min Chaul Moon, Joon Yeob Lee and II Je Yu \\ Toxicological Research Center, Hoseo University, Asan 336-795, Korea
}

(Received May 10, 2010; Revised May 14, 2010; Accepted May 15, 2010)

\begin{abstract}
Nanoparticle exposure assessment presents a unique challenge in the field of occupational and environmental health. With the commercialization of nanotechnology, exposure usually starts from the workplace and then spreads to environment and consumer exposure. This report discusses the current trends of nanoparticle exposure assessment, including the definition of nanotechnology relevant terms, essential physicochemical properties for nanomaterial characterization, current international activities related nanomaterial safety, and exposure assessment standard development for nanotechnology. Further this report describes challenges of nanoparticle exposure assessment such as background measurement, metrics of nanoparticle exposure assessment and personal sampling.
\end{abstract}

Key words: Nanoparticle, Exposure, Assessment, Nanomaterial, Standards, Nanotechnology

\section{INTRODUCTION}

Nanoparticle exposure assessment presents a unique challenge in the field of occupational and environmental health. When compared with bulk particles or conventional particles, nanoparticle sampling and exposure assessment require quite different methods from those conventionally used in occupational and environmental health, as shown in Table 1. Yet, there is currently no consensus on the best sampling method for characterizing manufactured nanoparticle exposure. There are also no accepted quantitative occupational exposure levels (OELs) for manufactured nanomaterials, although company-developed occupational exposure levels and benchmark doses based on toxicity data are beginning to emerge. Meanwhile, qualitative assessments comparing particle concentrations at the emission source and background particle concentrations are frequently used to find measures for exposure mitigation. Furthermore, there are no established metrics for evaluating airborne nanoparticle exposure. The conventional mass dose-based airborne concentration is insufficient for quantitative exposure assessment, since nanoparticles are known to be more reactive due to their wide surface and number per mass when compared with large conventional particles. Accordingly, this report discusses the current trends of nanoparticle exposure assessment, including the definition, physicochemical properties, current international activities, and exposure assess-

Correspondence to: II Je Yu, Hoseo University, 165 Sechul-ri, Baebang-myun, Asan 336-795, Korea

E-mail: u1670916@chollian.net ment standard development.

\section{TERMS AND DEFINITIONS OF NANOMATERIALS}

ISO TS 27687 (2009) and KS A 27687 (2010) both offer definitions of nano objects, as presented in Table 2 and Fig. 1. Notwithstanding, the definition of a nanomaterial is still an on going topic within the ISO TC 229 Working group 1.

\section{PHYSICOCHEMICAL PROPERTIES OF NANOMATERIALS}

As described in the terms and definitions of nanomaterials, nanomaterials are easily agglomerated (due to weak forces, such as van-der Waals or simple physical entanglement) or aggregated (due to strong forces, such as covalent bonds or bonds resulting from sintering or complex physical entanglement) after formation. Currently, the OECD WPMN (working party on manufactured nanomaterials) SG 3 (steering group 3) is conducting "Safety testing of a representative set of manufactured nanomaterials" and has recommended a basic data set for the physicochemical properties described in Table 2. Meanwhile, the ISO TC 229 working group 3 has a project titled "Guidance on physico-chemical parameters of manufactured nanomaterials for toxicologic assessment", which also recommends 8 physico-chemical Parameters (Table 3). As such, Table 3 compares the physicochemical parameters recommended by the GHS (2010, globally harmonized system on classification and labeling of chemicals), OECD WPMN DDP (dossier development plan), and ISO TC 229 working group 5, DTR (draft techni- 
Table 1. Comparison of sampling methods used for conventional particles and nanoparticles

\begin{tabular}{lll}
\hline \hline & Conventional particles & Nanoparticles \\
\hline Size & $500 \mathrm{~nm}$ - 10 micron & $100 \mathrm{~nm}$ 이하 \\
Respirable & respirable + inhalable & respirable \\
Sampling & personal > area & Personal < area \\
Sampling equipment & cyclone, impactor, filter & DMAS, CPC, OPC, APS, ELPI, filter \\
Sampling metric & mass, number (fiber) & number (particle, tube) mass, surface area \\
Background concentration & not usually measured & measured \\
Size distribution measurement & not usually analyzed & analyzed \\
TEM/SEM & not usually analyzed, except asbestos analysis & often performed \\
Process episode & not usually checked & checked and recorded \\
Emission source identification & easy & not easy to identified \\
\hline
\end{tabular}

Table 2. Terms and definitions of nano-objects

\begin{tabular}{|c|c|}
\hline Term & Definition \\
\hline nanoscale & size range from approximately $1 \mathrm{~nm}$ to $100 \mathrm{~nm}$ \\
\hline nano-object & material with one, two, or three external nanoscale dimensions \\
\hline particle & minute piece of matter with defined physical boundaries \\
\hline agglomerate & $\begin{array}{l}\text { collection of weakly bound particles or aggregates or mixtures of the two, where the resulting external surface area } \\
\text { is similar to the sum of the surface areas of the individual components }\end{array}$ \\
\hline aggregate & $\begin{array}{l}\text { particle comprising strongly bonded or fused particles, where the resulting external surface area may be signifi- } \\
\text { cantly smaller than the sum of the calculated surface areas of the individual components }\end{array}$ \\
\hline nanoparticle & nano-object with all three external dimensions on a nanoscale \\
\hline nanoplate & nano-object with one external dimension on a nanoscale and the two other external dimensions significantly larger \\
\hline nanofibre & nano-object with two similar external dimensions on a nanoscale and the third dimension significantly larger \\
\hline nanotube & hollow nanofibre \\
\hline nanorod & solid nanofibre \\
\hline nanowire & electrically conducting or semi-conducting nanofibre \\
\hline quantum dot & $\begin{array}{l}\text { crystalline nanoparticle that exhibits size-dependent properties due to quantum confinement effects on the elec- } \\
\text { tronic states }\end{array}$ \\
\hline
\end{tabular}

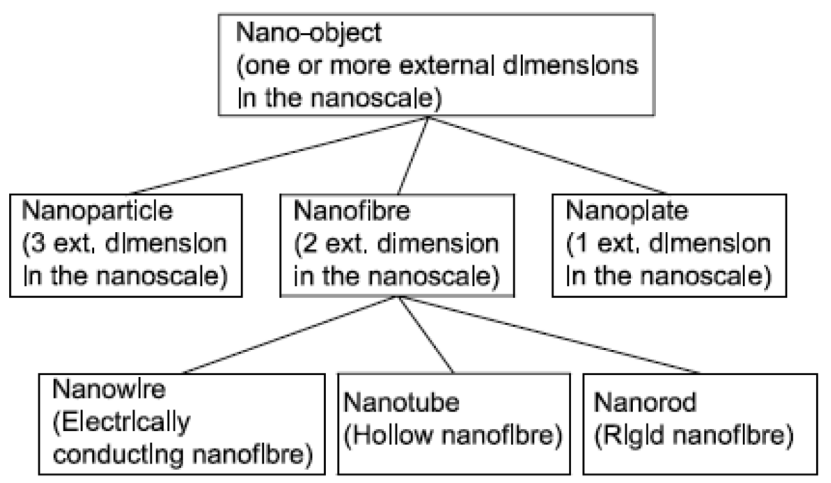

Fig. 1. Fragment of hierarchy of terms related to nano-objects.

cal report) 10314 .

\section{CURRENT INTERNATIONAL ACTIVITIES ON NANOPARTICLE EXPOSURE ASSESSMENT}

The OECD WPMN SG8 (Co-operation on Exposure Measurement and Exposure Mitigation) has already published several reports on nanoparticle exposure assessment, and recently asked member countries to participate in a exposure assessment sponsorship program: 1) to obtain exposure data to enable risk assessment of specific nanomaterials; 2) to evaluate the feasibility and necessity of developing a sponsorship program for exposure assessment; and 3) to facilitate the strategic planning of SG8 activities in the area of exposure measurements for generating data and guidance. The sponsors of the safety testing program were also asked to participate in the exposure assessment sponsorship program. Meanwhile, the ISO TC 229 has also conducted several activities relevant to the assessment of nanoparticle exposure, and ISO TR 12885 (2008) and ISO TS 12901 (2010) describe general guidelines for nanoparticle exposure assessment. However, there have been no activities as yet on the development of exposure assessment standards due to the continuing technical difficulties related to sampling and the characterization of nanoparticles.

\section{MEASUREMENT INSTRUMENTS}

Currently available devices and methods for the direct and indirect measurement of the number, mass, and surface area concentration are listed in Tables 5 and 6 (ISO TR 27628, 2007). 
Table 3. Physicochemical properties for chemicals described in GHS, and for nanomaterials, as recommended by OECD DDP and ISO TC 229 Project group 5 (DTR 10314)

\begin{tabular}{|c|c|c|}
\hline GHS & OECD DDP & ISO TC 229 DTR 10314 \\
\hline -appearance & -agglomeration/ & -particle size distribution \\
\hline -odour & aggregation: & -aggregation /agglomeration \\
\hline -odour threshold & -water solubility & -shape \\
\hline -melting $\mathrm{p}[$ point/freezing point & -crystalline phase & -composition \\
\hline -initial boiling point and boiling range & -dustiness: & -solubility/ dipsersibility \\
\hline -flash point & -crystallite size & -surface area \\
\hline -evaporation rate & -representative TEM picture(s) & -surface chemistry \\
\hline -flammability & -particle size distribution - dry and in relevant media & -surface charge density \\
\hline -upper/lower flammability or explosive limits & -specific surface area: & \\
\hline -vapour pressure & -zeta potential (surface charge) & \\
\hline -vapour density & -surface chemistry & \\
\hline -relative denstiy & -photocatalytic activity & \\
\hline -solubility & -pour density & \\
\hline -partition coefficient n-octanol/water & -porosity & \\
\hline -autoignition temp & -octanol-water partition coefficient & \\
\hline -decomposition temp & -redox potential & \\
\hline -viscosity & -radical formation potential & \\
\hline
\end{tabular}

Table 4. International activities on nanoparticle exposure assessment

\begin{tabular}{|c|c|c|}
\hline & & Relevant documents \\
\hline $\begin{array}{l}\text { OECD } \\
\text { WPMN }\end{array}$ & $\begin{array}{l}\text { SG8 (Co-operation } \\
\text { on Exposure Mea- } \\
\text { surement and Expo- } \\
\text { sure Mitigation) }\end{array}$ & $\begin{array}{l}\text {-Emission assessment for identification of sources and release of airborne manufactured nano- } \\
\text { mateirals in the workplace; compilation of existing guidance (No .11) } \\
\text {-Comparison of Guidance on Selection of Skin Protective Equipment and Respirators for Use in } \\
\text { the Workplace: Manufactured Nanomaterials }\end{array}$ \\
\hline ISO TC 229 & WG3 & $\begin{array}{l}\text {-TR 12885: Health and safety practices in occupational settings relevant to nanotechnologies } \\
\text {-TR 12901-1: Guide to safe handling and disposal of Manufactured Nanomaterials } \\
\text {-Nanomaterial Risk evaluation Framework } \\
\text {-DTS 12901-2: Guidelines for occupational risk management applied to engineered nanomateri- } \\
\text { als based on a "control banding approach } \\
\text {-DTR 13121: Nanomaterial risk evaluation process } \\
\text {-DTR } 13329 \text { :Preparation of MSDS for nanomaterials } \\
\text {-ISO TR 27628: Workplace atmosphere-ultrafine, nanoparticle and nano-structured aerosol-inha- } \\
\text { lation exposure characterization and assessment } \\
\text {-ISO 28439: Workplace atmosphere-characterization of ultra fine aerosols/nanoaerosols-Deter- } \\
\text { mining the size distribution and number concentration using differential electrical mobility ana- } \\
\text { lyzing systems }\end{array}$ \\
\hline UK & & $\begin{array}{l}\text {-UK British Standards Institute developed BSI PD 6699-2:2008: Guide to safe handling and dis- } \\
\text { posal of manufactured nanomaterials (http://www.bsi-global.com/en/Standards-and-Publications/ } \\
\text { Industry-Sectors/Nanotechnologies/). }\end{array}$ \\
\hline US & & $\begin{array}{l}\text {-US National Institute for Occupational Safety and Health released a second edition of } \\
\text { "Approaches to Safe Nanotechnology" in August, } 2006 \text { (http://www.cdc.gov/niosh/topics/nano- } \\
\text { tech/safenano/), which contains guidance for exposure measurements and exposure mitigation in } \\
\text { the workplace. } \\
\text {-ASTM WK8985(Technical Committee on Nanotechnology E56): Standard guide for handling } \\
\text { unbound engineered nanoparticles in occupational settings, 2007 }\end{array}$ \\
\hline Germany & & $\begin{array}{l}\text { German Chemical Industry Association (VCI) and German Federal Institute for Occupational } \\
\text { Safety and Health (BAuA) have developed a best practice guideline for handling and use of nano- } \\
\text { materials in the workplace (http://www.baua.de/nn_49456/en/Topics-from-A-to-Z/Hazardous- } \\
\text { Substances/Nanotechnology/pdf/guidance.pdf). } \\
\text { VCI is planning submission of New Work Item Proposals on standards for exposure measure- } \\
\text { ments to the ISO TC } 229 \text { WG3. }\end{array}$ \\
\hline
\end{tabular}


Table 5. Devices for direct measurement of number, mass, and surface area concentration (adapted from PD/ISO TR 27628)

\begin{tabular}{|c|c|c|}
\hline Metric & Device & Remarks \\
\hline \multirow{3}{*}{ Number } & $\begin{array}{l}\text { Condensation particle counter } \\
\text { (CPC) }\end{array}$ & $\begin{array}{l}\text { CPCs provide real-time number concentration measurements between their particle diame- } \\
\text { ter detection limits. They operate by condensing vapour onto sampled particles and detect- } \\
\text { ing/counting the droplets formed. Typically used with a } 1,000 \mathrm{~nm} \text { size selective inlet and } \\
\text { able to detect down to around } 10 \mathrm{~nm} \text {. }\end{array}$ \\
\hline & $\begin{array}{l}\text { Differential mobility particle } \\
\text { sizer (DMPS) }\end{array}$ & $\begin{array}{l}\text { Real-time size-selective (mobility diameter) detection of number concentration, giving num- } \\
\text { ber-based size distribution. }\end{array}$ \\
\hline & $\begin{array}{l}\text { Electron microscopy: (SEM, } \\
\text { TEM) }\end{array}$ & $\begin{array}{l}\text { Off-line analysis of electron microscope samples can provide information on size-specific } \\
\text { aerosol number concentration. }\end{array}$ \\
\hline \multirow[t]{2}{*}{ Mass } & Size selective static sampler & $\begin{array}{l}\text { Assessment of the mass of nanoparticles can be achieved using a size-selective personal } \\
\text { sampler with a cut-off point of approximately } 100 \mathrm{~nm} \text {, and the samples are then analyzed by } \\
\text { gravimetric weighing or a chemical analysis. Although a specific device of this type is not } \\
\text { yet commercially available, some cascade impactors (Berner-type low pressure impactors or } \\
\text { Microorifice impactors) have selection points around } 100 \mathrm{~nm} \text { and can be used in this way. }\end{array}$ \\
\hline & $\begin{array}{l}\text { Tapered element oscillating } \\
\text { microbalance (TEOM) }\end{array}$ & $\begin{array}{l}\text { Sensitive real-time monitors, such as the TEOM, can be used to measure the nanoaerosol } \\
\text { mass concentration on-line, with a suitable size-selective inlet }\end{array}$ \\
\hline \multirow{3}{*}{$\begin{array}{l}\text { Surface } \\
\text { area }\end{array}$} & Diffusion charger & $\begin{array}{l}\text { Real-time measurement of aerosol active surface area. Note that the active surface area does } \\
\text { not scale directly with the geometric surface area above } 100 \mathrm{~nm} \text {. Not all commercially } \\
\text { available diffusion chargers have a response that scales with a particle active surface area } \\
\text { below } 100 \mathrm{~nm} \text {. Diffusion chargers are only specific to nanoparticles if used with an appro- } \\
\text { priate inlet pre-separator. }\end{array}$ \\
\hline & $\begin{array}{l}\text { Electrostatic low pressure } \\
\text { impactor (ELPI) }\end{array}$ & $\begin{array}{l}\text { Real-time size-selective (aerodynamic diameter) detection of active surface area concentra- } \\
\text { tion. Note that the active surface area does not scale directly with the geometric surface-area } \\
\text { above } 100 \mathrm{~nm} \text {. }\end{array}$ \\
\hline & $\begin{array}{l}\text { Electron microscopy: (SEM, } \\
\text { TEM) }\end{array}$ & $\begin{array}{l}\text { An off-line analysis of electron microscope samples can provide information on the particle } \\
\text { surface area with respect to size. A TEM analysis provides direct information on the pro- } \\
\text { jected area of collected particles, which can be related to the geometric area for certain par- } \\
\text { ticle shapes. }\end{array}$ \\
\hline
\end{tabular}

Table 6. Devices for direct measurement of number, mass and surface area concentration (adapted from PD/ISO TR 27628)

\begin{tabular}{|c|c|c|}
\hline Metric & Device & Remarks \\
\hline Number & ELPI & $\begin{array}{l}\text { Real-time size-selective (aerodynamic diameter) detection of active surface-area concentration, giving } \\
\text { aerosol size distribution. Data may be interpreted in terms of the number concentration. } \\
\text { Size-selected samples may be further analyzed off-line. }\end{array}$ \\
\hline Mass & DMPS & $\begin{array}{l}\text { Real-time size-selective (aerodynamic diameter) detection of active surface area concentration, giving } \\
\text { aerosol size distribution. The mass concentration of aerosols can only be calculated if particle charge and } \\
\text { density are assumed or known. } \\
\text { Size-selected samples may be further analyzed off-line } \\
\text { Real-time size-selective (mobility diameter) detection of number concentration, giving aerosol size distri- } \\
\text { bution. The mass concentration of aerosols can only be calculated if particle shape and density are } \\
\text { known or assumed. }\end{array}$ \\
\hline $\begin{array}{l}\text { Sur- } \\
\text { face } \\
\text { area }\end{array}$ & $\begin{array}{l}\text { DMPS and ELPI } \\
\text { used in parallel }\end{array}$ & $\begin{array}{l}\text { Real-time size-selective (mobility diameter) detection of number concentration, giving aerosol size distri- } \\
\text { bution. The mass concentration of aerosols can only be calculated if particle shape and density are } \\
\text { known or assumed } \\
\text { The differences in the measured aerodynamic and mobility can be used to infer the particle fractal } \\
\text { dimension, which can be further used to estimate the surface area }\end{array}$ \\
\hline
\end{tabular}

\section{CHALLENGES OF NANOPARTICLE EXPOSURE ASSESSMENT}

Background measurement. Comparing the rnanoparticle concentration with the background concentration or the production-off concentration with the production-on con- centration has been recommended to evaluate the emission of nanoparticles in the workplace. If elevated concentrations of suspected nanoparticles are detected at potential emission sources relative to the background particle number concentrations, filter-based, source-specific air samples are then collected, where some are analyzed by electron 
microscopy (EM), such as Transmission EM (TEM) or Scanning EM (SEM), for particle identification and characterization, and the others are used to determine the elemental mass concentration. However, in real situations, measuring the background levels of nanoparticles is very hard, since (1) most workplaces are already in operation, (2) background measurements hinder the progress of normal work, (3) workplaces usually only allow 1 working day for exposure assessment, and (4) most workplaces are resistant to personal and area sampling. In some cases, the background concentration is even too high to distinguish (Lee et al., 2010). Thus, alternative methods need to be developed for measuring the background levels of nanoparticles.

Metrics of nanoparticle exposure assessment. Traditionally, the mass dose is used to interpret the airborne fine particle concentration, as the mass concentration usually corresponds well with the traditionally used occupational exposure levels or action levels, with the exception of asbestos and man-made mineral fibers (MMMFs), where the fiber number concentrations are used. However, due to their small size, nanoparticles have a much higher surface area and number of particles than the same mass of larger particles, making them potentially more reactive and more toxic. Thus, the nanomaterial surface area and number of nanoparticles have been proposed as better alternatives for characterizing exposure. However, the existence of heterogeneous particle species and various shapes of particle in the workplace atmosphere present problems as regards using the particle number and surface area parameters. The currently available surface area measuring devices are theoretically adapted to sphere-shaped particles, meaning that rod-shaped particles, like carbon nanotubes and carbon nanofibers, may not be appropriately evaluated. Meanwhile, the aggregation and agglomeration of nanoparticles in a workplace atmosphere create problems as regards counting the proper particle number.

Personal sampling. There are currently no validated personal samplers for evaluating exposure to nanoparticles. Thus, most documents relevant to exposure assessment published by international organizations refer to emission assessment based on area sampling or static sampling instead of exposure assessment. Without personal sampling, it is very difficult to asses exposure or set occupational exposure limits. While personal samplers are now being developing, they will only be available a few years later. Thus, in the meantime, the assessment of workplace exposure needs to combine sampling methods, such as traditional personal sampling and area or static sampling.

Occupational exposure levels. Although there are currently no OELs for nanoparticles, the BSI PD (2008) provides benchmark doses for certain nanomaterials, and the Bayer company has established voluntary OELs for
MWCNTs. Notwithstanding, there is still much debate over whether to use mass-based OELs or switch to surface areabased OELs. Yet, given the insufficiency of exposure data and lack of clear hazard data for nanomaterials, it is still too early to set valid OELs and even more difficult to execute any OELs without a proper exposure assessment method and metrics. Just last year, the OECD WPMN SG9 held a workshop in collaboration with the American Society of Risk Analysis on the risk assessment of nanomaterials and encountered many uncertainties in evaluating the risk of nanomaterials, due to the lack of physicochemical properties and hazard and exposure data when compared with conventional chemicals.

\section{PERSPECTIVES}

The development of exposure assessment methods for occupational exposure is the first step in establishing nanoparticle exposure assessment. With the commercialization of nanotechnology, exposure usually starts from the workplace and then spreads to environment and consumer exposure. Also, workplace exposure is less complex than environment or consumer exposure, although the magnitude of exposure is much higher than that with environment and consumer exposure. Exposure assessment methods developed for the workplace may also be directly or indirectly applicable to consumer exposure. To develop an exposure assessment methodology, personal sampling techniques, including nanoparticle-specific samplers, should first be developed. Such samplers need to be able to calculate the number or area concentration, as well as the mass concentration, either simultaneously or separately. Second, characterizing the proper filter media for the efficient collection of manufactured nanomaterials according to their size, composition, and shape is needed, as there are currently no recommended guidelines or methods. Third, the behavior of manufactured nanoparticles in the workplace atmosphere should be investigated, as little is really known about the fate of nanoparticles released into the air during manufacture or introduced to nanomaterial-containing products. Thus, further studies on nanoparticle behavior are needed in real workplace and simulated conditions.

\section{ACKNOWLEDGEMENT}

This research was supported by the Academic Research fund of Hoseo University in 2009 (2009-135).

\section{REFERENCES}

British Standard Institution (BSI) PD (Public Document) 6699-1 (2007). Nanotechnologies - Part 1: Good practice guide for specifying manufactured nanomaterials. BSI, Londo.

British Standard Institution (BSI) PD (Public Document) 6699-2 (2007). Nanotechnologies - Part 2: Guide to safe handling and disposal of manufactured nanomaterials, BSI, London.

Globally harmonized system of classification and labeling of 
chemicals (GHS) (2010). United Nations. New York.

ISO TS 27687 (2008). Nanotechnologies - Terminology and definitions for nano-objects - Nanoparticle, nanofibre and nanoplate. ISO, Geneva.

ISO DTR 10314 (2010). Nanotechnologies - Guidance on Physico-chemical parameters of manufactured nanomaterials for toxicologic assessment. ISO, Geneva.

ISO TR 12885 (2008). Nanotechnologies - Health and safety practices in occupational settings relevant to nanotechnologies. ISO, Geneva.

ISO DTS 12901 (2010). Nanotechnologies - Guide to safe handling and disposal of manufactured nanomaterials - Part 1:
Guide to safe handling and disposal of manufactured nanomaterials. ISO, Geneva.

ISO TR 27628 (2007). Nanotechnologies - Workplace atmosphereultrafine, nanoparticle and nano-structured aerosols-inhalation exposure characterization and assessment, ISO, Geneva.

KS A 27687 (2008). Nanotechnologies - Terminology and definitions for nano-objects - Nanoparticle, nanofibre and nanoplate. Korea Standard Association, Seoul.

Lee, J.H., Lee, S.B., Bae, G.N., Jeon, J.S., Yoon, J.U., Ji, J.H., Sung, J.H., Lee, B.G., Lee, J.H., Yang, J.S., Kim, H.Y., Kang, C.S. and Yu, I.J. (2010). Exposure assessment of carbon nanotube manufacturing workplaces. Inhalation Toxicology, 22, 369-381. 